\title{
Reliability of MR Imaging-Based Posterior Fossa and Brain Stem Measurements in Open Spinal Dysraphism in the Era of Fetal Surgery
}

\author{
(D) M. Aertsen, (D). Verduyckt, (D) F. De Keyzer, (D) T. Vercauteren, (DF. Van Calenbergh, (D). De Catte, (D). Dymarkowski, \\ (D)P. Demaerel, and (iD). Deprest
}

\begin{abstract}
BACKGROUND AND PURPOSE: Fetal MR imaging is part of the comprehensive prenatal assessment of fetuses with open spinal dysraphism. We aimed to assess the reliability of brain stem and posterior fossa measurements; use the reliable measurements to characterize fetuses with open spinal dysraphism versus what can be observed in healthy age-matched controls; and document changes in those within 1 week after prenatal repair.
\end{abstract}

MATERIALS AND METHODS: Retrospective evaluation of 349 MR imaging examinations took place, including 274 in controls and 52 in fetuses with open spinal dysraphism, of whom 23 underwent prenatal repair and had additional early postoperative MR images. We evaluated measurements of the brain stem and the posterior fossa and the ventricular width in all populations for their reliability and differences between the groups.

RESULTS: The transverse cerebellar diameter, cerebellar herniation level, clivus-supraocciput angle, transverse diameter of the posterior fossa, posterior fossa area, and ventricular width showed an acceptable intra- and interobserver reliability (intraclass correlation coefficient $>0.5$ ). In fetuses with open spinal dysraphism, these measurements were significantly different from those of healthy fetuses (all with $P<.0001)$. Furthermore, they also changed significantly ( $P$ value range $=.01$ to $<.0001$ ) within 1 week after the fetal operation with an evolution toward normal, most evident for the clivus-supraocciput angle $\left(65.9 \pm 12.5^{\circ} ; 76.6 \pm 10.9 ; P<.0001\right)$ and cerebellar herniation level $(-9.9 \pm 4.2 \mathrm{~mm} ;-0.7 \pm 5.2 ; P<.0001)$.

CONCLUSIONS: In fetuses with open spinal dysraphism, brain stem measurements varied substantially between observers. However, measurements characterizing the posterior fossa could be reliably assessed and were significantly different from normal. Following a fetal operation, these deviations from normal values changed significantly within 1 week.

ABBREVIATIONS: $\mathrm{ACi}=$ atriocerebral index $\mathrm{CHL}=$ cerebellar herniation level; $\mathrm{CSA}=$ clivus-supraocciput angle; $\mathrm{GA}=$ gestational age; $\mathrm{ICC}=$ intraclass correlation coefficient; $\mathrm{OSD}=$ open spinal dysraphism; $\mathrm{PF}=$ posterior fossa; $\mathrm{TCD}=$ transverse cerebellar diameter; $\mathrm{TDPF}=$ transverse diameter of the PF; $\mathrm{VW}=$ ventricular width

O pen spinal dysraphism (OSD), subdivided into myelomeningocele and myeloschisis, is a nonlethal congenital malformation with complex physical and neurodevelopmental sequelae. Its prevalence is approximately 4.9 per 10,000 live births in Europe and 3.17 in the United States. ${ }^{1-3}$ OSD results in motor and sensory deficits, their extension being defined by the upper level

Received May 29, 2018; accepted after revision October 6.

From the Department of Imaging and Pathology (M.A., J.V., F.D.K., S.D., P.D.), Clinical Department of Radiology, University Hospitals KU Leuven, Leuven, Belgium; School of Biomedical Engineering and Imaging Sciences (T.V.), King's College, London; Department of Neurosurgery (F.V.C.), University Hospitals Leuven, Leuven, Belgium; Academic Department of Development and Regeneration, Cluster Woman and Child (L.D.C., J.D.), Group Biomedical Sciences, KU Leuven, Leuven, Belgium; and Institute for Women's Health, University College London, (J.D.), London, UK.

Philippe Demaerel and Jan Deprest are shared last authors.

J. Deprest was partly funded by the Great Ormond Street Hospital Charity Fund. The work was also supported by the Engineering and Physical Sciences Research Council and the Innovative Engineering for Health award by the Wellcome Trust. of the anatomic defect. These range, as the level increases, from bladder, bowel, and sexual dysfunction to involvement of the lower and even upper extremities and secondary orthopedic disabilities. ${ }^{4,5}$ Children with OSD almost invariably have an associated Chiari II hindbrain malformation and ventriculomegaly. ${ }^{6}$ The Chiari II malformation is characterized by posterior fossa (PF) and brain stem abnormalities with downward displacement and compression of the cerebellum and brain stem. ${ }^{7}$

Geerdink et $\mathrm{al}^{8}$ demonstrated that morphometric measures reliably quantify the morphologic distortions of Chiari II malformation on postnatal MR images. The mamillopontine distance and the cerebellar width were the most sensitive and specific de-

Please address correspondence to Michael Aertsen, MD, Department of Radiology, Herestraat 49, 3000 Leuven, Belgium; e-mail: michael.aertsen@uzleuven.be

三 Indicates article with supplemental on-line tables.

http://dx.doi.org/10.3174/ajnr.A5930 
terminants of Chiari II. ${ }^{9}$ Some fetuses with OSD have ventriculomegaly, and its degree is believed to be predictive of the need for postnatal shunting. ${ }^{10,11}$

In 2011, the Management of Myelomeningocele Study (MOMS) demonstrated the benefit of in utero repair of myelomeningocele because the need for ventricular shunting at 12 months was reduced and motor outcome at 30 months improved. ${ }^{12}$ Fetuses with the suspicion of OSD should be assessed comprehensively to counsel parents about the expected outcome and possibility of fetal surgery. In this assessment, fetal MR imaging has a crucial role to characterize the brain and spinal abnormalities and rule out additional anomalies in fetuses with OSD. ${ }^{13,14}$ For fetal surgery eligibility, the presence of Chiari II hindbrain malformation on MR imaging is a necessary finding. ${ }^{12,15}$ Many measurements have been proposed to describe the typical PF changes in fetuses with OSD, yet the reproducibility of these has rarely been studied. ${ }^{14,16-23}$ These parameters have also been shown to change after in utero repair of OSD in small series and at different time points after fetal surgery, yet no study has consistently reported early postoperative assessment in utero. ${ }^{18}$

The aims of this study were 3-fold: 1) to assess the reproducibility of measurements of the brain stem and PF that have been suggested to be representative on postnatal ${ }^{8,9}$ and prenatal MR imaging $^{14,16-23} ; 2$ ) to apply those parameters that were shown to be reproducible, to discriminate fetuses with OSD from gestational age-matched fetuses with a normal PF; and 3) to document early changes in these measurements 1 week after a fetal operation.

\section{MATERIALS AND METHODS}

This was a single-center retrospective study at University Hospitals Leuven that was approved by its ethics committee (S60814). Patients eligible for the OSD group were those having fetal MR imaging examinations for additional assessment because of a prenatal diagnosis of OSD on ultrasound. Before MR imaging, patients had an ultrasound assessment, in which the lesion, secondary changes, and, when applicable, associated anomalies were characterized. Before the MR imaging, the radiologist was informed of the ultrasound findings. For the gestational agematched controls, we included fetuses assessed for other congenital anomalies that do not affect the central nervous system or who were scanned for suspected CNS abnormalities with normal findings on prenatal ultrasound, fetal MR imaging, and postnatal evaluation (On-line Table 1).

\section{Fetal Imaging and Quality Criteria}

The routine protocol for this condition includes acquisition on a 1.5T MR imaging system (Aera; Siemens, Erlangen, Germany) with 2 small body coils placed adjacent to each other over the maternal abdomen. The mother was positioned in the supine or left lateral decubitus position. The images used were T2-weighted HASTE or balanced steady-state gradient-echo sequences in the sagittal, axial, and coronal planes relative to the fetal head. Before September 2015, maternal sedation (flunitrazepam, $0.5 \mathrm{mg}$ orally 20-30 minutes before the examination) was used when the gestational age (GA) was $<30$ weeks. ${ }^{24}$ Later, this was abandoned because we, like others, thought that this induced maternal adverse effects while not clinically required. ${ }^{25}$ For this study, we searched our data base for all examinations performed in the setting of spinal dysraphism assessment, as well as for appropriate gestational age-matched controls. The image quality had to be good, consisting of at least 3 orthogonal T2-weighted HASTE series of the fetal brain with limited fetal motion, allowing adequate performance of the outcome measurements. The primary selection and review of images was performed by a single pediatric radiologist (M.A.) with $>3$ years of experience in fetal MR imaging. The main exclusion criteria were twin pregnancy, syndromal pathology, fetal hydrops, or anhydramnios. The number of patients and individual reasons for exclusion are shown in On-line Table 2. This exclusion left data from 349 MR imaging examinations of a total of 1006, including 274 examinations in 246 control fetuses. These data illustrate that some fetuses were scanned more than once. Additionally, we included 52 MR imaging examinations in fetuses with OSD, of whom 23 had a repeat MR imaging examination after the operation. The eligibility criteria for fetal surgery were those used in the MOMS trial. ${ }^{12}$

\section{Outcome Measurements}

Biometric variables included the transverse cerebellar diameter (TCD), pontine thickness, and pontine height, measured according to the standards defined by Garel ${ }^{26}$ and Tilea et al. ${ }^{27}$ The transverse diameter of the PF (TDPF) was measured according to Woitek et al, ${ }^{17}$ who suggested that this would be a proxy for the TCD. The midsagittal PF area was measured according to Tsai et al. $^{20}$ The ventricular width (VW) was measured in the coronal plane according to Garel, ${ }^{26}$ and in case of asymmetry, the largest value was taken into account. Mamillopontine distance, the level of kinking of the brain stem, medullary length, tentorial length, and width of the cisterna magna were measured as described by Geerdink et al. ${ }^{8}$ The width of the foramen magnum was defined as the distance between the opisthion and the basion. The cerebellar herniation level (CHL) was measured by drawing a perpendicular line from the foramen magnum to the lowest cerebellar portion. In the presence of cerebellar herniation, the deepest portion was measured. ${ }^{20}$ The clivus-supraocciput angle (CSA) was measured according to D'Addario et al. ${ }^{28}$ The TCD, TDPF, mamillopontine distance, TL, PF area, and CSA are demonstrated in Fig 1.

\section{Reproducibility Study}

The reproducibility of measurements was determined on a randomly chosen subgroup of spinal dysraphism cases $(n=15 / 52$; referred to as the pilot group). Images were anonymized and uploaded to a research server ${ }^{29}$ for assessment by M.A. and J.V., a radiologist with 1-year specific training for fetal MR imaging. This radiologist was first trained with a training dataset from 5 other fetuses with spinal dysraphism, with the help of a purposely designed training document. For intraobserver assessment, M.A. read the images twice in a random order with a 2 -week interval. J.V. measured parameters with at least moderate (intraclass correlation coefficient $[\mathrm{ICC}]>0.5$ ) intraobserver reliability once to obtain interobserver reliability. ${ }^{30}$ 


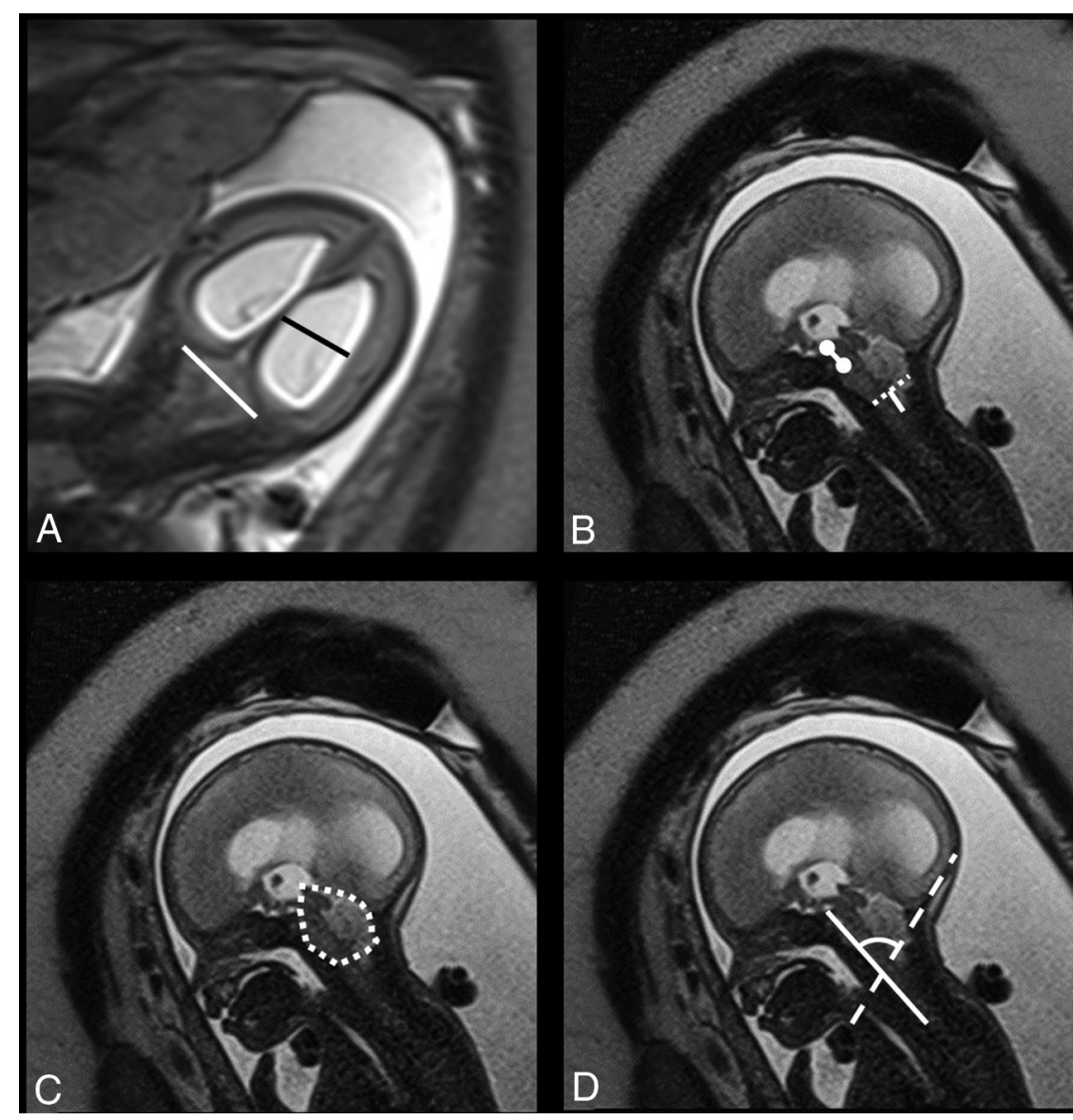

FIG 1. T2-weighted imaging (HASTE) in the coronal ( $A$ ) plane shows the biparietal diameter (white line in $A$ ) and the ventricular width (black line in $A$ ). In the sagittal plane (B-D), the mamillopontine distance (white line with circles at both ends in $B$ ) is demonstrated along with the foramen magnum diameter (dotted white line in $B$ ) and the cerebellar herniation level (white line perpendicular to the dotted line in $B$ ). The midsagittal posterior fossa area is shown in $C$ (dotted free form), and the clivus-supraocciput angle is demonstrated in $D$ with a line according to the clivus (white line) and the occiput (dotted line).

\section{Posterior Fossa Characteristics}

The PF characteristics were determined on the presumed healthy population to obtain normative values. To compare cases of fetal myelomeningocele with the healthy population, we used these normative curves to calculate expected values for the given gestational ages, and the fetal myelomeningocele values were then expressed as observed over the expected ratio.

\section{Short-Term (<7 Days) Postoperative Changes}

In this part of the study, we looked at the difference between PF measurements shown to be reproducible in the above part of the study in 23 fetuses who had a fetal operation at our center. These fetuses had preoperative MR imaging and were imaged again within 1 week after the operation. All measurements were performed on T2-weighted images in the coronal or sagittal plane of the fetal head. Again, the values were expressed as observed over the expected ratio to determine changes after prenatal treatment that were not attributable to normal growth.

In addition to the posterior fossa, we also evaluated the ventricular width in fetuses with OSD and the difference from the control population. To describe the differential effect of a fetal operation on the parenchyma and ventricles, one can measure changes in the so-

\section{Demographics}

called atriocerebral index (ACi). The ACi is the ratio of the atrial diameter and the cerebral (parenchymal) biparietal diameter. ${ }^{24}$ Others called this index the ventricular width index as used in the postnatal literature. ${ }^{18}$

\section{Statistics}

Intraobserver and interobserver variability were analyzed with a 2-way random ICC using SPSS for Windows, Version 22.0 (Released 2004; IBM, Armonk, New York). An ICC cutoff value of 0.5 as the lowest acceptable was chosen, taking into account the guidelines for interpretation by Cicchetti ${ }^{31}$ and allowing some variation in view of the limited spatial resolution for assessing such small structures so that borderline parameters can be fully investigated. For the interpretation of ICC values, we followed the guidelines of Koo and $\mathrm{Li}^{30}{ }^{30}$ with ICC values $<0.5$ indicative of poor reliability; values between 0.5 and 0.75 , moderate reliability; values between 0.75 and 0.9 , good reliability; and values $>0.90$, excellent reliability. The normality of GA in the 274 examinations was evaluated using the Shapiro-Wilk test, which indicated that GA was not normally distributed. We attempted several transformation models (logarithmic, polynomial, and square root) from which the square root transformation provided the most normally distributed data. Afterward, regression analysis was performed on all examined PF characteristics to find normative ranges in correlation with GA. Differences in the reliable parameters between the healthy cohort and the fetuses with OSD were calculated using the Wilcoxon-Mann-Whitney test. The Wilcoxon test was used to analyze differences in the paired measurements of individual fetuses before and after the operation. All statistics in the PF characteristics section were performed using Analyze-it (Analyze-it for Microsoft Excel 4.81.4; Analyze-it Software, Leeds, UK). A P value $<.05$ indicated statistical significance.

\section{RESULTS}

MR imaging examinations in controls were performed at a mean GA of $27.9 \pm 5.3$ weeks (range,18.6-38.3 weeks). In fetuses with OSD, the mean GA at MR imaging was $23.6 \pm 0.3$ weeks (range, 19.3-27.3 weeks). Descriptive statistics for the study parameters in controls and cases with OSD are shown in Table 1.

\section{Reproducibility Study}

The intraobserver ICCs for the PF area, VW, TCD, and CHL were excellent. Conversely, TDPF (0.729), the pontine thickness (0.59), 
Table 1: Mean and SDs of different parameters for the controls and fetuses with nonoperated and operated spinal dysraphism

\begin{tabular}{lccc}
\hline & $\begin{array}{c}\text { Controls } \\
(\boldsymbol{n}=274)\end{array}$ & $\begin{array}{c}\text { Nonoperated } \\
\text { OSD }(\boldsymbol{n}=52)\end{array}$ & $\begin{array}{c}\text { Postoperative } \\
\text { OSD }(\boldsymbol{n}=\mathbf{2 3})\end{array}$ \\
\hline GA $(\mathrm{wk})$ & $27.9(5.3)$ & $23.6(0.3)$ & $26.0(1.1)$ \\
VW $(\mathrm{mm})$ & $6(1.6)$ & $11.9(4.6)$ & $12.3(3.6)$ \\
PF area $\left(\mathrm{cm}^{2}\right)$ & $7.4(2.2)$ & $3.1(0.9)$ & $4.44(0.83)$ \\
TDPF $(\mathrm{mm})$ & $39.8(7.1)$ & $22.3(3.4)$ & $27.2(4.1)$ \\
TCD $(\mathrm{mm})$ & $31.6(6.4)$ & $21.8(3)$ & $24.4(3.3)$ \\
Ratio TCD/TDPF & $0.79(0.05)$ & $1(0.05)$ & $0.9(0.07)$ \\
CHL $(\mathrm{mm})$ & $8.8(1.9)$ & $-9.3(5.4)$ & $-0.7(5.2)$ \\
CSA & $87.1^{\circ}\left(8.3^{\circ}\right)$ & $62.5^{\circ}\left(9.7^{\circ}\right)$ & $76.6^{\circ}\left(10.9^{\circ}\right)$ \\
\hline
\end{tabular}

Table 2: Equations of the regression curves with their respective levels of significance and the $\mathbf{R}^{2}$ for the TCD, CHL, CSA, TDPF, PF area, VW, and ratio TCD/TDPF

\begin{tabular}{llll}
\multicolumn{1}{c}{ Parameter } & \multicolumn{1}{c}{ Regression Curve } & $\begin{array}{c}\boldsymbol{P} \\
\text { Value }\end{array}$ & \multicolumn{1}{c}{$\mathbf{R}^{2}$} \\
\hline TCD & $y=64.38-30.58^{*} x+4.606^{*} x^{2}$ & $<.0001$ & 0.907 \\
CHL & $y=-78.26+31.6^{*} x-2.849^{*} x^{2}$ & $<.0001$ & 0.117 \\
CSA & $y=21.61+12.44^{*} x$ & $<.0001$ & 0.265 \\
TDPF & $y=-65.28+19.95^{*} x$ & $<.0001$ & 0.894 \\
PF area & $y=14.25-8.537^{*} x+1.369^{*} x^{2}$ & $<.0001$ & 0.875 \\
VW & $y=51.5-17.59^{*} x+1.692^{*} x^{2}$ & .0257 & 0.027 \\
Ratio TCD/TDPF & $y=3.87-1.215^{*} x+0.1192^{*} x^{2}$ & $<.0001$ & 0.243 \\
\hline
\end{tabular}

Note:- $x$ indicates square root (gestational age in weeks); $R^{2}$, coefficient of determination

${ }^{\text {a }} P$ value according to Fisher $F$ test.

the foramen magnum diameter (0.44), mamillopontine distance (0.66), CSA (0.60), and the width of the cisterna magna (0.48) had a fair-to-good reproducibility. Measurements of the other parameters showed a low reproducibility (tentorial length) or were unreliable (level of brain stem kinking, medullar length, and pontine length). Interobserver reproducibility was moderate for TCD, CHL, CSA, and TDPF. PF area and VW had good interrater reliability.

\section{Posterior Fossa Characteristics}

All parameters with an intra- and interobserver ICC $\geq 0.5$ were taken into account for further analysis. Normative curves for VW, PF area, TDPF, TCD, CSA, TCD/TDPF, and CHL were calculated and are shown in Table 2. Figure 2 shows the individual observations for cases with OSD, which were all significantly different from what was measured in healthy fetuses $(P<.0001)$.

\section{Short-Term (<7 Days) Postoperative Changes}

When we considered the observed over expected ratio values, fetal surgery was associated with a significant difference in cerebellar herniation $(P<.0001)$, TCD/TDPF $(P=.0002)$, TCD $(P=$ $.0127), \mathrm{PF}$ area $(P=.0003), \mathrm{TDPF}(P=.0127), \mathrm{CSA}(P<.0001)$, and VW $(P=.0002)$. Figure 3 shows the individual observations and boxplots in patients with OSD for all tested parameters, both pre- and postoperatively. In 18/23 (78\%) fetuses, the postoperative observed over expected ratios of the PF area were improving toward normal compared with the preoperative measurement. The same was true for the observed over expected ratios of the TDPF in 15/23 (65\%), for the observed over expected ratios of the TCD in $7 / 23(30 \%)$, and for the observed over expected TCD/ TDPF ratios in 4/23 (17\%) postoperative fetuses. The observed over expected ratio level of cerebellar herniation increased, meaning that the Chiari II-associated changes were reduced in 19/23 fetuses at 1 week after the operation. The observed over expected ratios of the CSA increased toward, the normal range in $16 / 23$ (70\%) postoperative fetuses. The VW increased in 17/23 (74\%) fetuses, but there was no difference in the ACi between the preand postoperative examinations $(P=.46)$, with a mean of the preoperative measurements of 0.22 and, postoperatively, of 0.23 .

\section{DISCUSSION}

A large number of structural measurements on MR images of the PF have been suggested to characterize changes attributed to OSD. Some are believed to be clinically relevant due to their relation to the symptoms associated with a small PF, Chiari II malformation, and brain stem compression. ${ }^{32}$ These changes are represented by the degree of cerebellar herniation, mamillopontine distance, brain stem kinking, tentorial hypoplasia, and the configuration of the fourth ventricle. These features can be measured reproducibly in the postnatal period. ${ }^{8}$ In the era of prenatal diagnosis and fetal surgery, logically, the same measurements are also used. Yet, in case of prenatal surgery, these are measured on midgestational prenatal images at a time when the condition is still progressive and image quality is different. We therefore investigated whether those measurements were reproducible in the window of interest. For instance, we did not evaluate the fourth ventricle because it is hardly visible around 20-24 weeks in fetuses with OSD. Conversely, we looked at parameters characterizing the brain stem (mamillopontine distance, pontine thickness, pontine length, foramen magnum diameter, level of brain stem kinking, medulla length, tentorial length, and cisterna magna width) and the PF as a whole (TCD, TDPF, PF area, CHL, $\mathrm{TCD} / \mathrm{TDPF}$, and CSA). Due to its clinical relevance in fetuses with OSD and the impact on outcome after fetal surgery, ${ }^{33}$ we also included the VW.

Herein, we conclude that brain stem parameters in fetuses with OSD cannot be measured reliably at midgestation; thus, we were not able to objectively measure brain stem elongation and displacement in utero. For fetuses with OSD, we believe this issue is due to the limited spatial resolution of fetal MR imaging at that point in gestation when the structures involved are in the millimetric range so that the slightest measurement error has a tremendous impact on statistics. Another reason is that in OSD, there is a decrease or even absence of extra-axial CSF, further limiting the contrast resolution of MR imaging. ${ }^{34}$ Contrast resolution is essential for accurate evaluation of small PF structures as well as some additional cerebral lesions due to the presence of different structures (medulla oblongata, pons, vermis, cerebellum) in a small area. ${ }^{35}$ There is no difference between balanced steady-state free-precession sequences and half-Fourier rapid relaxation with relaxation enhancement sequences for measuring the foramen magnum. ${ }^{19}$ Conversely, when we looked at larger structures (PF area, TCD, and TPFD) and/or with more abundant contrast between fluid and soft tissue (CHL and VW), the ICC values were much better. We confirmed this finding for those parameters typical for the smaller posterior fossa and cerebellar descent in the pathologic subgroup, as others did. ${ }^{17,18,20,22}$ Moreover, the difference with our gestational age-matched healthy patients was highly significant, again as previously described. ${ }^{17}$

Fetal surgery has been shown to reverse those posterior fossa 

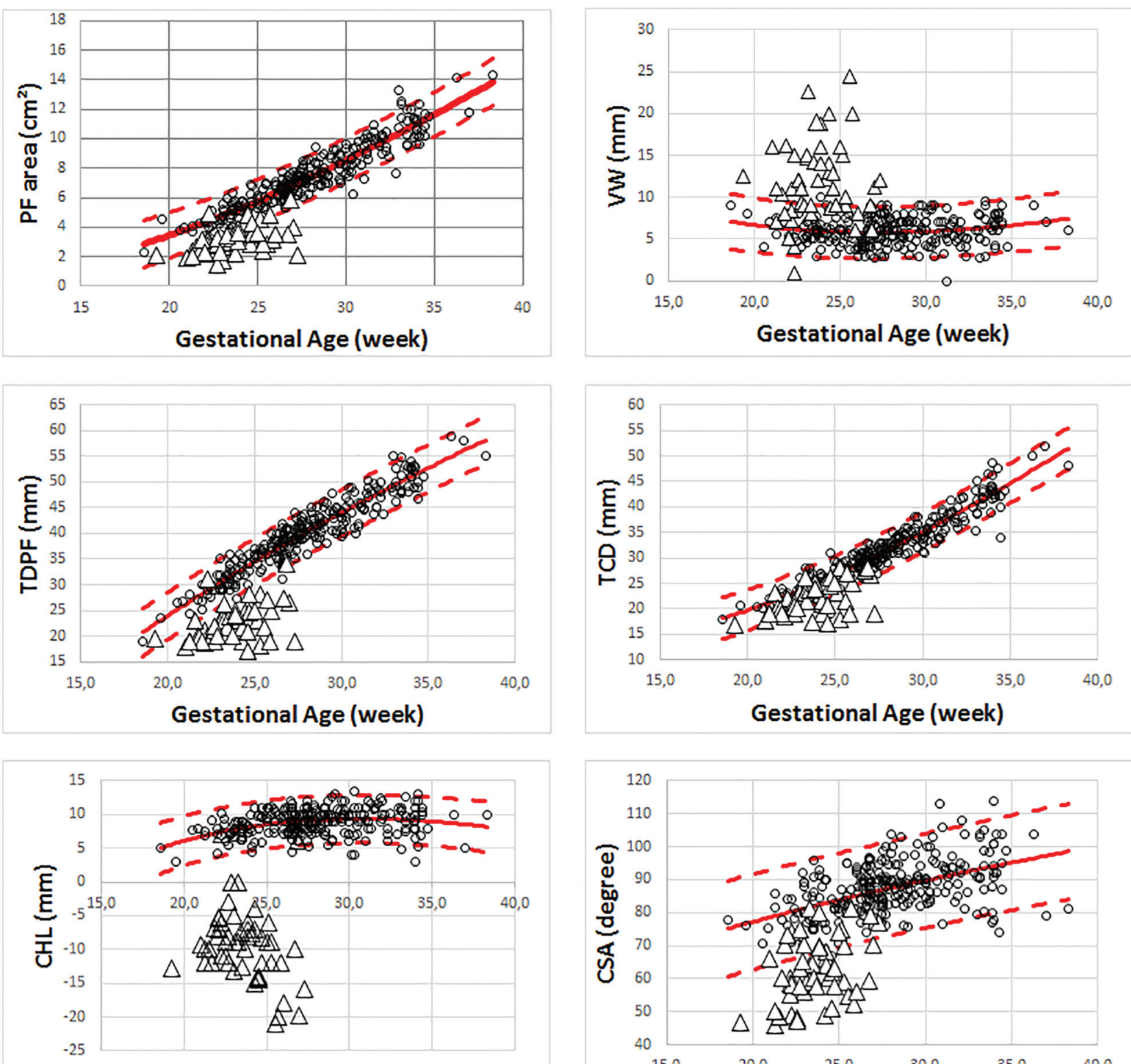

Gestational Age (week)

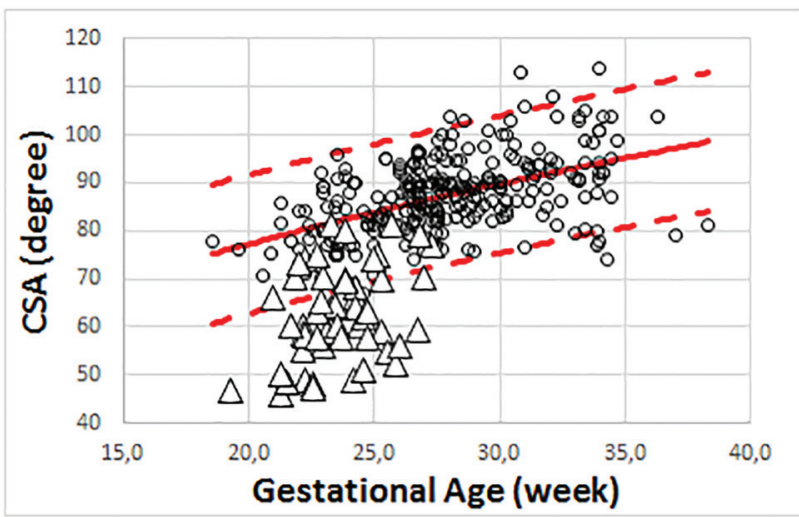

FIG 2. The individual observations in the control population (black circles) with the mean (full line) and $95 \%$ confidence interval (dashed lines) compared with the preoperative fetuses with open spinal dysraphism (white triangles) for the posterior fossa area, ventricular width, transverse diameter of the posterior fossa, transverse cerebellar diameter, cerebellar herniation level, and clivus-supraocciput angle.

changes. ${ }^{11,14,18}$ Other investigators used the above parameters to measure those typically $\geq 4$ weeks after the operation. ${ }^{18}$ In the present study, we acquired images within 2 weeks. In line with ultrasound observations, we quantified significant changes during that short observation period. Within 1 week, $26 \%$ of operated fetuses had a PF area within the normal range, and in 52\%, the TCD was normal. Furthermore, the cerebellar herniation level was at or above the foramen magnum in 52\% of fetuses, and $70 \%$ had a normal CSA. These acute changes in the PF following closure of the defect are in line with the theory of McLone and Knepper. ${ }^{36}$ In other words, it seems that the effects of fetal surgery on the PF are already evident and can be quantified very early postoperatively. They are very likely to persist because others observed the same effects later on and even confirmed them after birth. ${ }^{14,18,37}$ This outcome might be an interesting proxy for measurement of the efficacy of fetal surgery in clinical studies.

In this short-term follow-up study, we observed a postoperative increase in ventricular width within 1 week in most patients. Such increase is in line with observations made by others, though several weeks after fetal surgery. ${ }^{18,33}$ They suggest that there is still a certain degree of obstructive ventricular widening. The dynamics of CSF fluid production and resorption in OSD are still poorly understood. It may take some time after fetal surgery for CSF fluid circulation to normalize after stopping its egress. ${ }^{11}$

In healthy fetuses, the ACi drops dramatically between 24 and 27 weeks, which means that there is, during that time period, a proportional increase in the parenchymal brain component. In our patients undergoing fetal surgery, the ACi remained stable. 

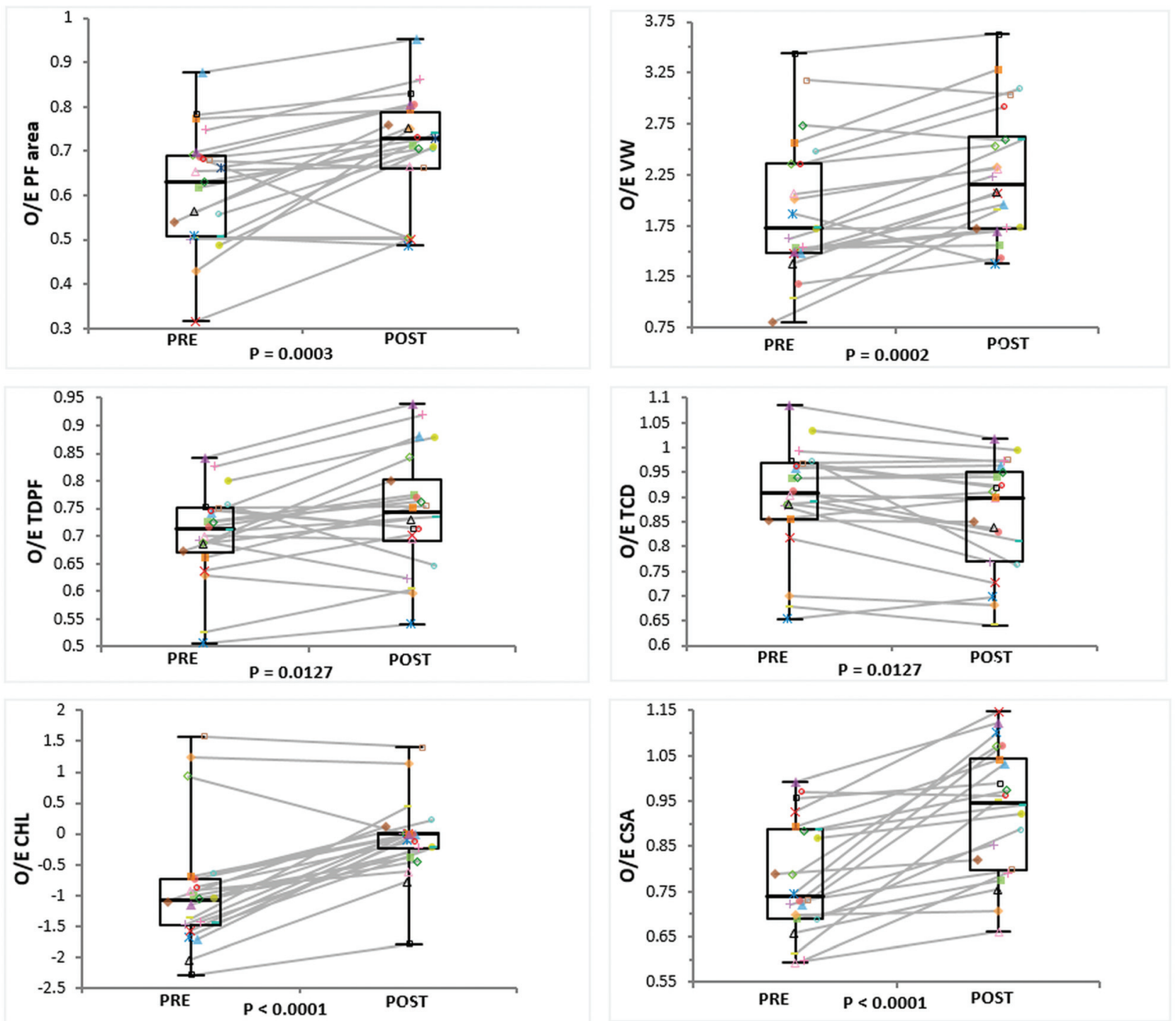

FIG 3. Boxplot demonstrating the minimum, first quartile, median, third quartile, and maximum of the observed over expected ratio in preoperative fetuses with open spinal dysraphism and postoperative fetuses with OSD at 1 week for the posterior fossa area, ventricular width, transverse diameter of the posterior fossa, transverse cerebellar diameter, cerebellar herniation level, and clivus-supraocciput angle.

This might be counterintuitive and contradicts the findings of Rethmann et al. ${ }^{18}$ They measured the ACi and observed a drop in the ACi; yet, that was 4 weeks after the operation and continued after birth. These contrasting findings can be explained in different ways. A drop in ACi would suggest a proportional increase in biparietal cerebral diameter, hence a larger parenchymal component. Conversely, the increase in ACi for a comparable VW in our cohort would suggest that the parenchymal component decreases. Although tempting, both groups cannot be compared because measurements were performed at different gestational ages. In healthy fetuses, the ACi spontaneously declines between 24 and 27 weeks. If fetuses with OSD follow this normal evolution, our findings may eventually align with these of Rethmann et al and can be explained by spontaneous and normal evolution. Unfortunately, we have no longitudinal follow-up MR images to further study these observations.

We have looked into prenatal measurements characterizing the brain stem, which, to our knowledge, was not performed in detail before. We based our evaluation on our own normative values. Furthermore, we documented all parameters in a relatively large pathologic population in the narrow gestational age range that is relevant to prenatal spina bifida repair. Although the number of operated fetuses was not very large, we were able to describe early postoperative changes therein. There are, however, some shortcomings. First, our control fetuses definitely had normal CNS findings on both MR imaging and ultrasound but were not truly fully healthy fetuses. Controls underwent MR imaging because of other congenital abnormalities, presumed not to be associated with CNS abnormalities.

Second, we did not report on advanced MR images, such as DWI and DTI, which may also provide relevant information. We definitely acknowledge the potential of DWI and DTI because they may detect more subtle abnormalities below the anatomic level. Woitek et $\mathrm{al}^{38}$ already showed that fetuses with spina bifida have increased fractional anisotropy compared with normally developing fetuses, however without reporting the functional im- 
pact. Although we acquired such sequences in fetuses with spina bifida, we were lacking those in healthy fetuses or the controls used in this study; hence, we could not interpret the findings. Third, we describe in utero findings without correlation to postnatal short- or long-term follow-up or early postnatal MR imaging confirmation. Although relevant, such a follow-up was beyond the scope of this study as was a comparison of these posterior fossa measurements with those in a cohort that underwent postnatal repair. Postnatal evaluation would most likely have identified additional findings, such as subependymal heterotopias. ${ }^{18,39}$ These are often missed in utero before as well as after fetal surgery.

\section{CONCLUSIONS}

This study showed that the brain stem cannot be reliably characterized using the current panel of measurements in fetuses with OSD. Conversely, posterior fossa measurements are demonstrated to be reliable in the evaluation of fetuses with OSD. In addition, these were significantly different from those in the healthy population and changed within 7 days after prenatal surgery. This finding advocates for their use in the evaluation of fetuses with OSD on fetal MR imaging on a routine basis before and shortly after a prenatal operation.

Disclosures: Tom Vercauteren-UNRELATED: Employment: University College London, Comments: main employer for the duration of this work; Grant: Wellcome Trust (WT101957)/Engineering and Physical Sciences Research Council (NS/A000027/ 1*), Comments: Support for Travel to Meetings for the Study or Other Purposes: Wellcome Trust/Engineering and Physical Sciences Research Council, Comments: travel support from the listed grant funding, ${ }^{\star}$ Luc De Catte-UNRELATED: Employment: consultant to Feto-Maternal Medicine AZ St-Jan Brugge, Comments: 1 day/2 weeks clinical activity.* Philippe Demaerel—UNRELATED: Board Membership: Editorial Board of Neuroradiology. Jan Deprest-RELATED: Other: Great Ormond Street Hospital Children's Charity, Comments: This grant pays part of my academic (research) time to my institution*; UNRELATED: Grants/Grants Pending: MEDRI, Wellcome Trust, Comments: We have a grant on the use of advanced imaging techniques in fetal surgery (Wellcome) and a research grant on novel implant materials for Holder of a research chair "POPART" (Pelvic Organ Prolapse - Advanced Research and Technology) - sponsored by MEDRI*; Travel/Accommodations/Meeting Expenses Unrelated to Activities Listed: Chiesi Farmaceutici, Comments: paid travel and accommodations to the Sharing Progress in Neonatology 2018 meeting.* *Money paid to the institution.

\section{REFERENCES}

1. Garne E, Loane M, Addor M-C, et al. Congenital hydrocephalus: prevalence, prenatal diagnosis and outcome of pregnancy in four European regions. Eur J Paediatr Neurol 2010;14:150-55 CrossRef Medline

2. Khoshnood B, Loane M, de Walle H, et al. Long term trends in prevalence of neural tube defects in Europe: population-based study. BMJ 2015;351:h5949 CrossRef Medline

3. Canfield MA, Mai CT, Wang Y, et al; National Birth Defects Prevention Network. The association between race/ethnicity and major birth defects in the United States, 1999-2007. Am J Public Health 2014;104:e14e-23 CrossRef Medline

4. Oakeshott P, Hunt GM. Long-term outcome in open spina bifida. Br J Gen Pract 2003;53:632-36 Medline

5. Rintoul NE, Sutton LN, Hubbard AM, et al. A new look at myelomeningoceles: functional level, vertebral level, shunting, and the implications for fetal intervention. Pediatrics 2002;109:1-7 CrossRef Medline

6. Mitchell LE, Adzick NS, Melchionne J, et al. Spina bifida. Lancet 2004;364:1885-95 CrossRef Medline

7. Barkovich AJ, Congenital malformations of the brain and skull. In: Barkovich AJ, ed, Ovid Technologies, Inc. Pediatric Neuroimaging. 4th ed. Philadelphia: Lippincott Williams \& Wilkins; 2005:374-84
8. Geerdink N, van der Vliet T, Rotteveel JJ, et al. Essential features of Chiari II malformation in MR imaging: an interobserver reliability study, Part 1. Childs Nerv Syst 2012;28:977-85 CrossRef Medline

9. Geerdink N, van der Vliet T, Rotteveel JJ, et al. Interobserver reliability and diagnostic performance of Chiari II malformation measures in MR imaging, Part 2. Childs Nerv Syst 2012;28:987-95 CrossRef Medline

10. Biggio JR Jr, Wenstrom KD, Owen J. Fetal open spina bifida: a natural history of disease progression in utero. Prenat Diagn 2004;24: 287-89 CrossRef Medline

11. Bruner JP, Tulipan N, Reed G, et al. Intrauterine repair of spina bifida: preoperative predictors of shunt-dependent hydrocephalus. Am J Obstet Gynecol 2004;190:1305-12 CrossRef Medline

12. Adzick NS, Thom EA, Spong CY, et al; MOMS Investigators. A randomized trial of prenatal versus postnatal repair of myelomeningocele. N Eng J Med 2011;364:993-1004 CrossRef Medline

13. Saleem SN, Said AH, Abdel-Raouf M, et al. Fetal MRI in the evaluation of fetuses referred for sonographically suspected neural tube defects (NTDs): impact on diagnosis and management decision. Neuroradiology 2009;51:761-72 CrossRef Medline

14. Sutton LN, Adzick NS, Bilaniuk LT, et al. Improvement in hindbrain herniation demonstrated by serial fetal magnetic resonance imaging following fetal surgery for myelomeningocele. JAMA 1999;282: 1826-31 CrossRef Medline

15. Heuer GG, Moldenhauer JS, Scott Adzick NS. Prenatal surgery for myelomeningocele: review of the literature and future directions. Childs Nerv Syst 2017;33:1149-55 CrossRef Medline

16. Danzer E, Adzick NS. Fetal surgery for myelomeningocele: patient selection, perioperative management and outcomes. Fetal Diagn Ther 2011;30:163-73 CrossRef Medline

17. Woitek R, Dvorak A, Weber M, et al. MR-based morphometry of the posterior fossa in fetuses with neural tube defects of the spine. PLOS One 2014;9:e112585 CrossRef Medline

18. Rethmann C, Scheer I, Meuli M, et al. Evolution of posterior fossa and brain morphology after in utero repair of open neural tube defects assessed by MRI. Eur Radiol 2017;27:4571-80 CrossRef Medline

19. Abele TA, Lee SL, Twickler DM. MR imaging quantitative analysis of fetal Chiari II malformations and associated open neural tube defects: balanced SSFP versus half-Fourier RARE and interobserver reliability. J Magn Reson Imaging 2013;38:786-93 CrossRef Medline

20. Tsai T, Bookstein FL, Levey E, et al. Chiari-II malformation: a biometric analysis. Eur J Pediatr Surg 2002;12(Suppl 1):S12-18 Medline

21. Osuagwu FC, Lazareff JA, Rahman S, et al. Chiari I anatomy after ventriculoperitoneal shunting: posterior fossa volumetric evaluation with MRI. Childs Nerv Syst 2006;22:1451-56 CrossRef Medline

22. Grant RA, Heuer GG, Carrión GM, et al. Morphometric analysis of posterior fossa after in utero myelomeningocele repair. J Neurosurg Pediatr 2011;7:362-68 CrossRef Medline

23. Chen SC, Simon EM, Haselgrove JC, et al. Fetal posterior fossa volume: assessment with MR imaging. Radiology 2006;238:9971003 CrossRef Medline

24. Garel C. Methodology. In: Carel C, Delezoide AL, Delezoide V, eds. MRI of the Fetal Brain. Berlin: Springer-Verlag; 2004

25. Saleem SN. Fetal MRI: an approach to practice-a review. J Adv Res 2014;5:507-23 CrossRef Medline

26. Garel C. Fetal cerebral biometry: normal parenchymal findings and ventricular size. Eur Radiol 2005;15:809-13 CrossRef Medline

27. Tilea B, Alberti C, Adamsbaum C, et al. Cerebral biometry in fetal magnetic resonance imaging: new reference data. Ultrasound Obstet Gynecol 2009;33:173-81 CrossRef Medline

28. D'Addario V, Pinto V, Del Bianco A, et al. The clivus-supraocciput angle: a useful measurement to evaluate the shape and size of the fetal posterior fossa and to diagnose Chiari II malformation. Ultrasound Obstet Gynecol 2002;18:146-49 Medline

29. Doel T, Shakir DI, Pratt R, et al. GIFT-Cloud: A data sharing and 
collaboration platform for medical imaging research. Comput Methods Programs Biomed 2017;139:181-90 CrossRef Medline

30. Koo TK, Li MY. A guideline of selecting and reporting intraclass correlation coefficients for reliability research. J Chirop Med 2016; 15:155-63 CrossRef Medline

31. Cicchetti DV. Guidelines, criteria, and rules of thumb for evaluating normed and standardized assessment instruments in psychology. Psychological Assessment 1994;6:284-90 CrossRef

32. Stevenson KL. Chiari type II malformation: past, present, and future. Neurosurg Focus 2004; 16:E5 Medline

33. Tulipan N, Wellons JC 3rd, Thom EA, et al; MOMS Investigators. Prenatal surgery for myelomeningocele and the need for cerebrospinal fluid shunt placement. J Neurosurg Pediatr 2015;16:613-20 CrossRef Medline

34. Danzer E, Johnson MP, Bebbington M, et al. Fetal head biometry assessed by fetal magnetic resonance imaging following in utero myelomeningocele repair. Fetal Diagn Ther 2007;22:1-6 CrossRef Medline
35. Limperopoulos C, Tworetzky W, McElhinney DB, et al. Brain volume and metabolism in fetuses with congenital heart disease: evaluation with quantitative magnetic resonance imaging and spectroscopy. Circulation 2010;121:26-33 CrossRef Medline

36. McLone DG, Knepper PA. The cause of Chiari II malformation: a unified theory. Pediatr Neurosci 1989;15:1-12 CrossRef Medline

37. Nagaraj UD, Bierbrauer KS, Zhang B, et al. Hindbrain herniation in Chiari II malformation on fetal and postnatal MRI. AJNR Am J Neuroradiol 2017;38:1031-36 CrossRef Medline

38. Woitek R, Prayer D, Weber M, et al. Fetal diffusion tensor quantification of brain stem pathology in Chiari II malformation. Eur Radiol 2016;26:1274-83 CrossRef Medline

39. Nagaraj UD, Peiro JL, Bierbrauer KS, et al. Evaluation of subependymal gray matter heterotopias on fetal MRI. AJNR Am J Neuroradiol 2016;37:720-75 CrossRef Medline 